\title{
Effect of $\mathrm{Na}_{2} \mathrm{SO}_{4}$ on Structure and Corrosion Resistance of Ceramics Coatings Containing Zirconium Oxide on Ti-6Al-4V Alloy
}

\author{
Zhongping Yao, ${ }^{\dagger}$ Zhaohua Jiang, and Xuelin Zhang \\ Department of Applied Chemistry, Harbin Institute of Technology, Harbin 150001, China
}

\begin{abstract}
A micro-plasma oxidation (MPO) technique has been developed in recent years, by which ceramic coatings are reported to possess improved properties and promising application prospects in many fields. The aim of this work was to study the effect of sodium sulfate, as an additive in the zirconate system, on the structure and corrosion resistance of ceramics coatings containing zirconium oxide grown on $\mathrm{Ti}-6 \mathrm{Al}-4 \mathrm{~V}$ by MPO process. The phase composition, morphology, and element distribution in the coating were investigated by X-ray diffractometry, scanning electron microscopy, and energy distribution spectroscopy. Meanwhile, the corrosion resistance of the coated samples was examined by polarizing curves and potentiodynamic anodic curves in $3.5 \% \mathrm{NaCl}$ solution. The results show that ceramic coatings were composed of $m-\mathrm{ZrO}_{2}, t-\mathrm{ZrO}_{2}$, and $\mathrm{KZr}_{2}\left(\mathrm{PO}_{4}\right)_{3}$. The $\mathrm{Ti}$ content in the coating near the substrate decreased sharply, and then remained at $5 \mathrm{wt} \%$ or so through the coating, while the $\mathrm{Zr}$ content near the substrate increased greatly, and then remained at about $55 \mathrm{wt} \%$ through the coating. The addition of sodium sulfate did not change the composition of the coatings, but increased the relative proportion of zirconium oxide to $\mathrm{KZr}_{2}\left(\mathrm{PO}_{4}\right)_{3}$ in the coating. Sodium sulfate decreased the thickness of the coating, while improving the density of the coatings. Moreover, the addition of the sodium sulfate improved the corrosion resistance of the coated samples in a $3.5 \% \mathrm{NaCl}$ solution, whether considering localized pitting corrosion resistance or uniform corrosion resistance.
\end{abstract}

\section{Introduction}

$\mathrm{T}$ HERE is much recent interest about micro-plasma oxidation (MPO) because of the excellent properties of the ceramic coatings produced by this technique and many promising application prospects in many fields such as aviation, naval vessels, biomedicine, chemical industry, and so on. ${ }^{1-4}$ At present, much research is being focused on the preparation and properties of the ceramic coatings in widely adopted electrolytes such as phosphate, aluminate, silicate, or their mixed solutions, ${ }^{5-7}$ under different kinds of MPO electric source modes and the electric parameters. ${ }^{8-12}$ There are only a few instances of research of the MPO technique on $\mathrm{Al}$ alloys in the zirconate system, ${ }^{13}$ while similar work on $\mathrm{Ti}$ and its alloys has seldom been reported. Therefore, we prepared compound ceramic coatings containing zirconium oxide on Ti-6Al-4V alloy by pulsed single-polar MPO in a zirconate solution in our previous work. However, the coatings produced were coarse and loose due to the rapid MPO reaction rates, and the relative content of zirconium oxide was much lower in the coating. Sodium sulfate is a widely used

J. Smialek-contributing editor

Manuscript No. 20853. Received August 7, 2005; approved March 31, 2006. This work was financially supported by National Natural Science Foundation of China (Grant No. 50171026)

${ }^{\dagger}$ Author to whom correspondence should be addressed. e-mail: yaozhongping@ hit.edu.cn additive in electrochemical reactions, not only to improve the conductance of the solution but also to produce a weak passivation on the metals. ${ }^{2}$ Therefore, we selected sodium sulfate as an additive in the preparation of the coating to adjust the MPO reaction speed, and discussed the effect of sodium sulfate on the phase composition, structure, and corrosion resistance of the ceramic coatings.

\section{Experimental Procedure}

\section{(1) Preparation of the Ceramic Coatings on $\mathrm{Ti}-6 \mathrm{Al}-4 \mathrm{~V}$ by $\mathrm{MPO}$}

Plate samples of $\mathrm{Ti}-6 \mathrm{Al}-4 \mathrm{~V}$ with a dimension of $25 \mathrm{~mm} \times$ $15 \mathrm{~mm} \times 2 \mathrm{~mm}$ were first polished with abrasive paper, and then washed in $\mathrm{HF}-\mathrm{HNO}_{3}$ (1:1 in volume) aqueous solution. A home-made pulsed single-polar electrical source was used for MPO of the plate samples in a water-cooled electrolyzer made of stainless steel, which also served as the counterelectrode. The reaction temperature was controlled to below $30^{\circ} \mathrm{C}$ by adjusting the cooling water flow. The MPO process equipment used is similar to the one presented by Matthews and colleagues. ${ }^{1}$ The anode current density was fixed at $8 \mathrm{~A} / \mathrm{dm}^{2}$ and the frequency was maintained at $60 \mathrm{~Hz}$. An aqueous electrolyte was prepared from a solution of $\mathrm{K}_{2} \mathrm{ZrF}_{6}$ (concentration, $c=6 \mathrm{~g} / \mathrm{L}$ ), both with and without $\mathrm{Na}_{2} \mathrm{SO}_{4}$ (concentration, $c=3 \mathrm{~g} / \mathrm{L}$ ), and the $\mathrm{pH}$ of the solution was adjusted to $5-6$ by $\mathrm{H}_{3} \mathrm{PO}_{4}$. After the treatment, the coated samples were rinsed with water and dried in air.

\section{(2) Phase Composition and Structure of the Coatings}

The phase composition of the coatings was examined with X-ray diffraction (XRD) using a $\mathrm{Cu} K \alpha$ source. The morphology of the coatings and the elemental distribution were studied with scanning electron microscopy (SEM; Hitachi S-4700, Tokyo, Japan) and Philips EDAX energy dispersion spectroscopy (Eindhoven, the Netherlands), respectively. Coating thickness was measured using an Eddy current-based thickness gauge (CTG-10, Time Company, China), whose minimum resolution is $1 \mu \mathrm{m}$. The average thickness of each of the triplicate samples was obtained from 10 measurements at different positions.

\section{(3) Corrosion Resistance Properties}

An accelerated electrochemical method was evaluated in a threeelectrode cell (a Pt plate was used as a counter electrode, Ag/ $\mathrm{AgCl}$ reference electrode, and the coated sample as the working electrode). A CHI1140 electrochemical analyzer (Shanghai, China) was used to assess the corrosion resistance of the coated samples in aerated $3.5 \% \mathrm{NaCl}$ solution. General corrosion resistance of the coating was evaluated by polarization curves. The polarization curve scanning rate was $5 \mathrm{mV} / \mathrm{s}$, with a scanning range from minus $0.25 \mathrm{~V}$ of open circuit potential to plus $0.25 \mathrm{~V}$ of open circuit potential. Pitting corrosion resistance was evaluated by potentiodynamic anodic scanning curves. The suddenly rapidly potential during the positive scanning is named as broken potential $\left(E_{\mathrm{b}}\right)$, which is also called the pitting corrosion 
potential. The potential corresponding to the intersection of positive scanning curve and reverse scanning curve is named as protection potential $\left(E_{\mathrm{p}}\right)$. The pitting corrosion is determined by $E_{\mathrm{b}}$ : the larger the $E_{\mathrm{b}}$, the more the difficulty with which pitting corrosion occurs. The potentiodynamic loop area reflects the extent of development of the pitting corrosion after it occurs: the smaller the loop area, the better the pitting resistance the corresponding sample has. ${ }^{14-15}$ The potentiodynamic scanning rate was $20 \mathrm{mV} / \mathrm{s}$, with a potential increase from -1 to $10 \mathrm{~V}$, returning to $-1 \mathrm{~V}$, forming a potential-current density curve. Three parallel samples were used in each measurement of the corrosion resistance to ensure the reliability of experiments.

\section{Results}

\section{(1) Variation of Voltage of Anode Pulses Versus Time}

Figure 1 shows the curve of anode pulse voltage versus time. It is divided into parts: (1) rapidly ascending period to the spark voltage within 2-3 min, and then (2) slowly increasing period to the designed reaction time. It can be noted that the sodium sulfate decreased the anodic voltage throughout the MPO process.

\section{(2) Phase Composition of the Coatings}

Figure 2 shows the XRD patterns of the coatings. Clearly, the coating is composed of $m-\mathrm{ZrO}_{2}, t-\mathrm{ZrO}_{2}$, and $\mathrm{KZr}_{2}\left(\mathrm{PO}_{4}\right)_{3}$. The relative content of these phases is approximately evaluated through XRD analyses, with the results shown in Table I. The intensity of the XRD characteristic diffraction peaks of the coating was clearly lowered by adding sodium sulfate. Besides,

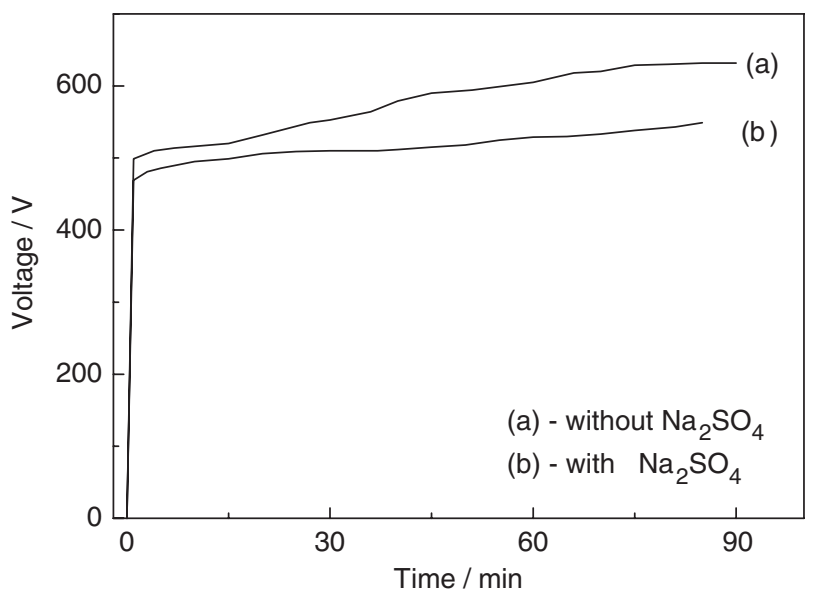

Fig. 1. Variation of voltage of anode pulses versus time.

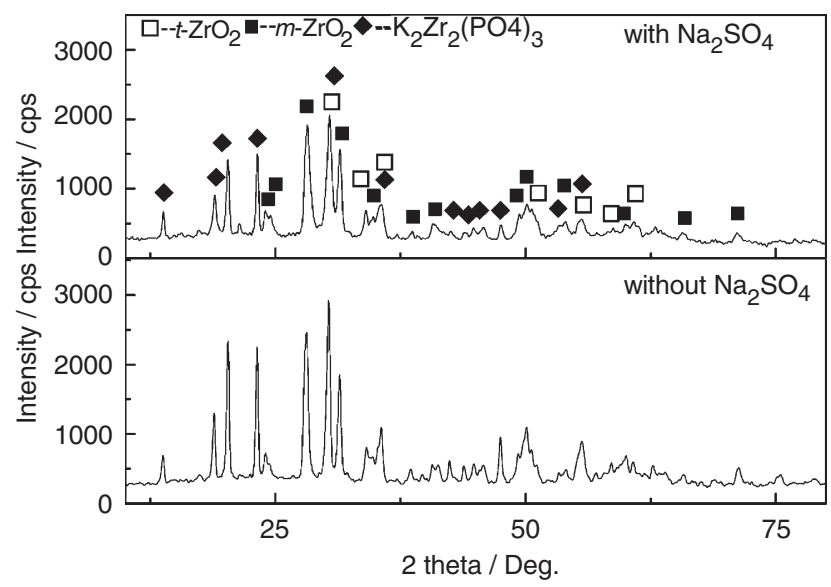

Fig. 2. X-ray diffraction patterns of the coatings.
Table I. Relative Phase Content (wt\%) of the Phases for the Ceramic Coatings With and Without $\mathrm{Na}_{2} \mathrm{SO}_{4}$

\begin{tabular}{lccc}
\hline & $m-\mathrm{ZrO}_{2}(\%)$ & $t-\mathrm{ZrO}_{2}(\%)$ & $\mathrm{KZr}_{2}\left(\mathrm{PO}_{4}\right)_{3}(\%)$ \\
\hline Without $\mathrm{Na}_{2} \mathrm{SO}_{4}$ & 4 & 37 & 59 \\
With $\mathrm{Na}_{2} \mathrm{SO}_{4}$ & 7 & 44 & 49 \\
\hline
\end{tabular}

sodium sulfate did not change the $\mathrm{Zr}$ content of the coatings, but the relative proportion of the phase composition. In other words, the relative content of $\mathrm{KZr}_{2}\left(\mathrm{PO}_{4}\right)_{3}$ was decreased while the relative content of zirconium oxide was increased in the coating.

\section{(3) Microstructure of the Coatings}

Sodium sulfate decreased the thickness of the coatings considerably: the mean thickness of the coating without $\mathrm{Na}_{2} \mathrm{SO}_{4}$ was about $206 \mu \mathrm{m}$, with an SD of 13.4, and that of the coating with $\mathrm{Na}_{2} \mathrm{SO}_{4}$ about $94.4 \mu \mathrm{m}$ (with an SD of 4.4 ), consistent with Fig. 3. For both conditions, the coating can be divided into an outer layer and an inner layer. The inner layer was dense and adhered to the substrate well, whereas the outer layer had some large holes and was so loose and dispersed that it was easily penetrated by the mounting resin. Actually, the thickness of the inner layer for both coatings was almost the same, and therefore, sodium sulfate decreased the thickness of the outer layer of the coating, and in the meantime the surface roughness of the coating was also decreased according to the SD of the thickness.
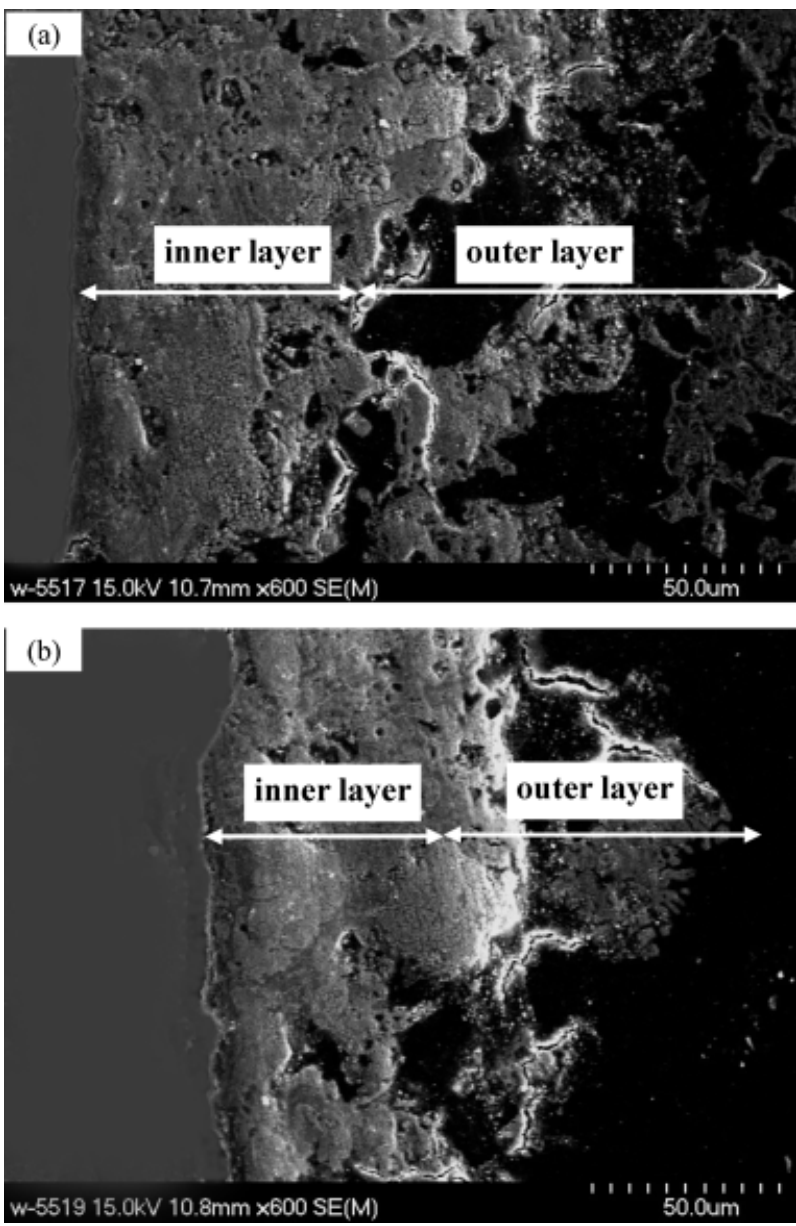

Fig. 3. Section images of the coatings (a) without $\mathrm{Na}_{2} \mathrm{SO}_{4}$ and (b) with $3 \mathrm{~g} / \mathrm{L}$ of $\mathrm{Na}_{2} \mathrm{SO}_{4}$. 


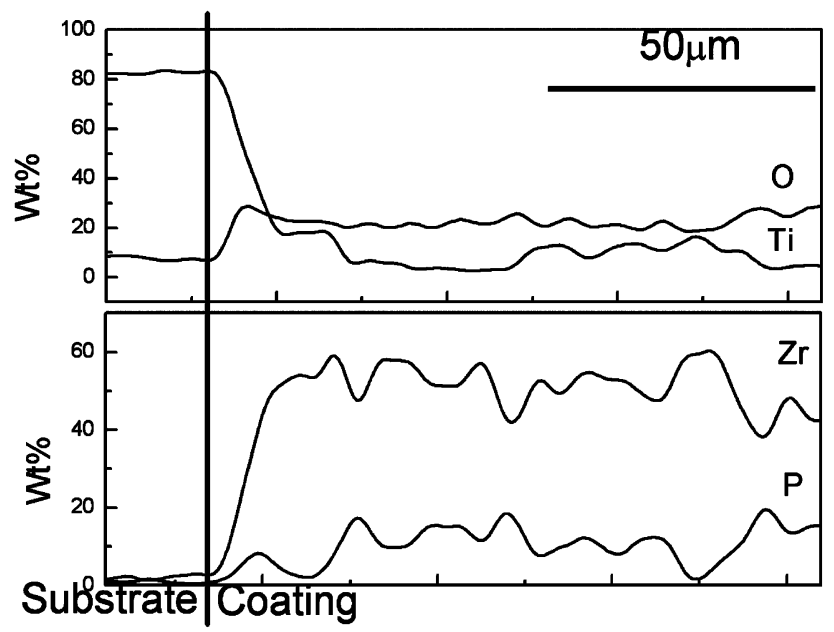

Fig. 4. Line scanning of the main elements in the coating.

\section{(4) Elemental Analysis of the Coating}

According to the EDAX energy spectrum, there is little influence of sodium sulfate on the elemental distribution. Therefore, only one of the results is shown in Fig. 4. The distribution of Ti and $\mathrm{Zr}$ changes greatly within $10 \mu \mathrm{m}$ or so from the interface; otherwise, the coating is uniform: with the Ti content remaining at 5 $\mathrm{wt} \%$ or so and the $\mathrm{Zr}$ content remaining at $55 \mathrm{wt} \%$ or so all throughout the coating. And $\mathrm{P}$ increased gradually toward the outer surface. The content of $\mathrm{O}$ remained at about $30 \mathrm{wt} \%$ throughout the whole coating.

\section{(5) Corrosion Resistance of the Coated Samples}

(A) General Corrosion Resistance of the Coated Samples: Polarizing curves of the coated samples and bare

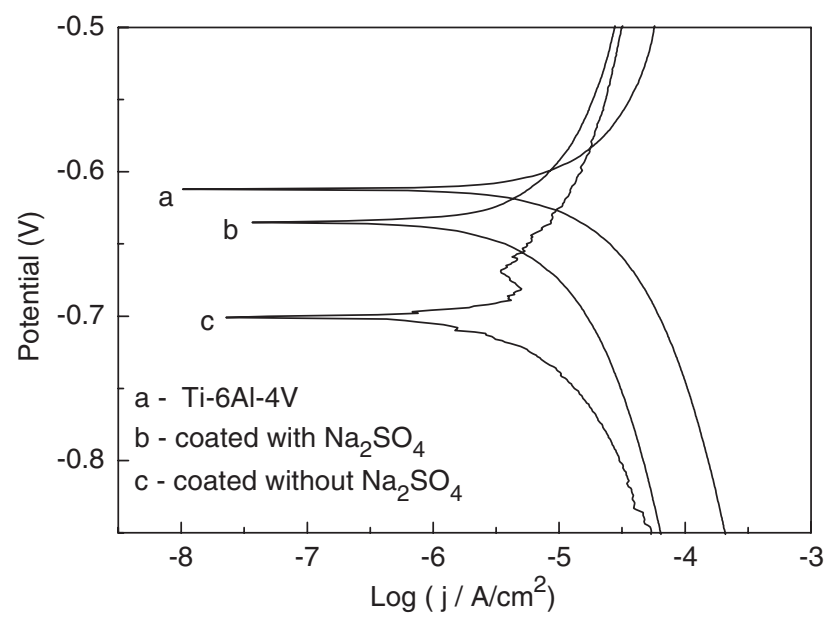

Fig. 5. Polarizing curves of the coated samples in an aerated $3.5 \%$ $\mathrm{NaCl}$ solution.

Table II. Corrosion Current Density and Corrosion Potential of the Coated Samples Under Different Concentrations of $\mathrm{Na}_{2} \mathrm{SO}_{4}$ in a $3.5 \% \mathrm{NaCl}$ Solution

\begin{tabular}{lcc}
\hline & $\begin{array}{c}\text { Corrosion current density } \\
\left(\times 10^{5} \mathrm{~A} / \mathrm{cm}^{2}\right)\end{array}$ & $\begin{array}{c}\text { Corrosion } \\
\text { potential }(\mathrm{V})\end{array}$ \\
\hline $\mathrm{Ti}-6 \mathrm{Al}-4 \mathrm{~V}$ & 1.625 & -0.583 \\
Without $\mathrm{Na}_{2} \mathrm{SO}_{4}$ & 1.851 & -0.784 \\
With $\mathrm{Na}_{2} \mathrm{SO}_{4}$ & 0.979 & -0.701 \\
\hline
\end{tabular}

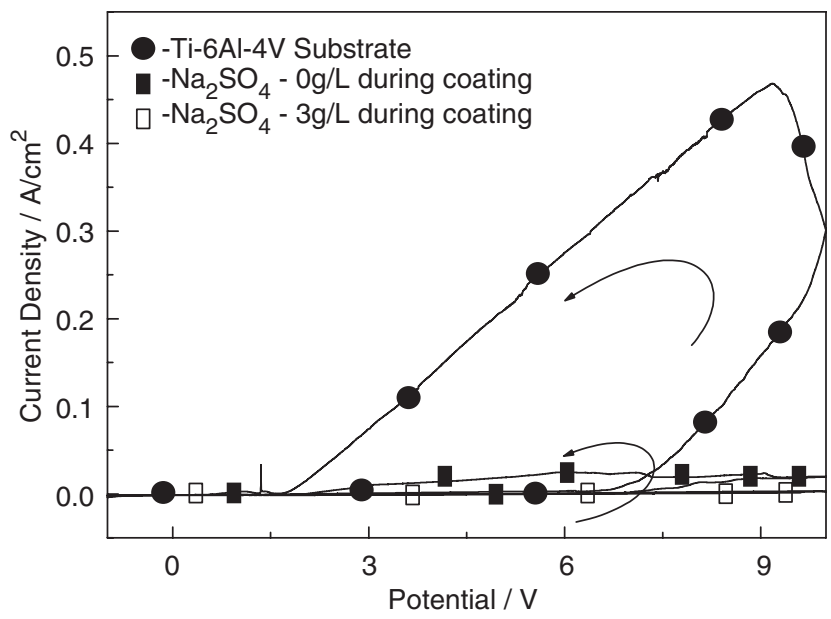

Fig. 6. Potentiodynamic anodic curves of the coated samples and $\mathrm{Ti}-6 \mathrm{Al}-4 \mathrm{~V}$ substrate in an aerated $3.5 \% \mathrm{NaCl}$ solution.

Table III. Area of Closed Potentiodynamic Anodic Curves of the Coated Samples and $\mathrm{Ti}-6 \mathrm{Al}-4 \mathrm{~V}$ Substrate in an Aerated $3.5 \%$ NaCl Solution

\begin{tabular}{lccc}
\hline & Ti-6Al-4V & Without $\mathrm{Na}_{2} \mathrm{SO}_{4}$ & With $\mathrm{Na}_{2} \mathrm{SO}_{4}$ \\
\hline Area & 1.716 & 0.1017 & 0.0060 \\
\hline
\end{tabular}

Ti-6Al-4V substrate are shown in Fig. 5. The corrosion current density and the corrosion potential of the coated samples and the substrate can be seen in Table II. The corrosion current density of the substrate is similar to that of the coated samples without $\mathrm{Na}_{2} \mathrm{SO}_{4}$, and lower than that of the coated samples without $\mathrm{Na}_{2} \mathrm{SO}_{4}$. The measured apparent area of all the samples was $1 \mathrm{~cm}^{2}$; however, the real area of the coated samples (here some further work is needed to gain an insight) was much more than that of the substrate because of the porosity of the coatings. Therefore, the corrosion current density of the substrate was actually higher than that of the coated samples, which meant that the general corrosion resistance of the coated samples was better than that of the substrate. As for the coated samples, it can be noted that the corrosion potential of the coated sample moved toward the positive with the addition of sodium sulfate in the electrolyte, which reduced the thermodynamic tendency of the corrosion. Meanwhile, the corrosion current density was also lessened. In a word, the general corrosion resistance of the coated samples was improved.

(B) Pitting Corrosion Resistance of the Ceramic Coatings: Figure 6 shows the potentiodynamic anodic scanning curves of the coated samples and $\mathrm{Ti}-6 \mathrm{Al}-4 \mathrm{~V}$ substrate. And Table III shows the area of closed curves of the coated samples and $\mathrm{Ti}-6 \mathrm{Al}-4 \mathrm{~V}$ substrate in an aerated $3.5 \% \mathrm{NaCl}$ solution. It can be noted that the pitting corrosion potentials of the coated samples are all higher than that of the bare Ti-6Al-4V substrate, which means that the MPO treatment improved the pitting corrosion resistance of $\mathrm{Ti}-6 \mathrm{Al}-4 \mathrm{~V}$ alloy. According to Table III, the area of the closed curve for the substrate is the largest, and the area of the closed curve with sodium sulfate is much smaller than that without sodium sulfate. Besides, under the same scanning voltage, the corresponding current density value with sodium sulfate is also much lower than that without sodium sulfate. Therefore, sodium sulfate improved the localized pitting corrosion resistance of the coated sample.

\section{Discussion}

Initially, a passivating film forms on the $\mathrm{Ti}-6 \mathrm{Al}-4 \mathrm{~V}$ anode surface upon immersion into an electrolyte. As the voltage is 
increased rapidly, the current remains constant until the breakdown voltage of the oxide film is reached. Then, the voltage is gradually increased, with stable sparking occurring uniformly across the surface, producing coating deposition and growth according to the MPO process. As a result of plasma thermochemical reactions with high temperature and high pressure occurring at the anode surface, here, $\mathrm{K}_{2} \mathrm{ZrF}_{6}+\mathrm{H}_{3} \mathrm{PO}_{4}$ electrolytes are oxidized at the anode surface to produce a mixture of $\mathrm{m}$ $\mathrm{ZrO}_{2}, t-\mathrm{ZrO}_{2}$, and $\mathrm{KZr}_{2}\left(\mathrm{PO}_{4}\right)_{3}$ oxide coating phases. Sodium sulfate additions both (1) increased the conductivity of the electrolyte, thus reducing the breakdown voltage, and (2) decreased the coating growth rate by its weakly passivating effect. Both of these features encourage a more stable coating process by reducing the intensity of the micro-plasma discharge.

The anodic polarization thus results in an oxidation reaction; $\mathrm{Ti}$ from the substrate and $\mathrm{Zr}$ from the electrolyte all participated in the MPO reaction. However, with the growth of the coating, the diffusion of $\mathrm{Ti}$ from the substrate to the coating and the diffusion of $\mathrm{Zr}$ from the solution into the coating became more and more difficult, therefore, first producing an enrichment of $\mathrm{Ti}$ in the oxide coating at the substrate surface, followed by higher levels of $\mathrm{Zr}$ through the coating. And the whole MPO process was accompanied by a large amount of $\mathrm{O}_{2}$ forming on the anode surface; meanwhile, several anions containing $\mathrm{O}$ participated in the reaction. Therefore, the content of $\mathrm{O}$ was almost constant throughout the coating. While high levels of both $\mathrm{ZrO}_{2}$ phases and $\mathrm{KZr}_{2}\left(\mathrm{PO}_{4}\right)_{3}$ phase were present in both coatings, $\mathrm{Na}_{2} \mathrm{SO}_{4}$ additions to the MPO electrolyte favored $\mathrm{ZrO}_{2}$ phases somewhat.

The electrochemical behavior indicates that both coatings were very effective, with somewhat better protectivity for the sample produced with $\mathrm{Na}_{2} \mathrm{SO}_{4}$. A higher applied potential needed to initiate corrosion, smaller current density, and reduced potentiodynamic loop area all suggest less electrolytic corrosion activity for the latter coating.

\section{Conclusion}

(1) This ceramic coating produced by the MPO process is composed of $m-\mathrm{ZrO}_{2}, t-\mathrm{ZrO}_{2}$, and $\mathrm{KZr}_{2}\left(\mathrm{PO}_{4}\right)_{3}$. The addition of sodium sulfate did not change the composition of the coatings, but increased the relative proportion of zirconium oxide to $\mathrm{KZr}_{2}\left(\mathrm{PO}_{4}\right)_{3}$.

(2) Sodium sulfate decreased the thickness of the coating, while decreasing the roughness of the coating.

(3) Sodium sulfate did not influence the elemental distribution. From the substrate to the surface, Ti in the coating decreased sharply, and then remained constant at $5 \mathrm{wt} \%$ or so, whereas $\mathrm{Zr}$ increased greatly, to about $55 \mathrm{wt} \%$.

(4) Processing with sodium sulfate addition improved the subsequent corrosion resistance of the coated samples in a $3.5 \%$ $\mathrm{NaCl}$ solution, whether considering uniform corrosion resistance or localized pitting corrosion resistance.

\section{References}

${ }^{1}$ A. L. Yerokhin, X. Nie, A. Leyland, A. Matthews, and S. J. Dowey, "Plasma Electrolysis for Surface Engineering," Surf. Coat. Technol., 122, 73-93 (1999).

${ }^{2}$ A. L. Yerokhin, X. Nie, A. Leyland, and A. Matthews, "Characterisation of Oxide Films Produced by Plasma Electrolytic Oxidation of a Ti-6Al-4V Alloy," Surf. Coat. Technol., 130, 195-206 (2000).

${ }^{3}$ G. Sundrarajan and L. Rama Krishna, "Mechanisms Underlying the Formation of Thick Alumina Coatings Through the MAO Coating Technology," Surf. Coat. Technol., 167, 269-77 (2003).

${ }^{4}$ W. B. Xue, Z. W. Deng, R. Y. Chen, and T. H. Zhang, "Review of Microarc Oxidation Technique on Surface of Non-Ferrous Metals," Heat Treatment Metals, 25 [1] 1-3 (2000) (in Chinese).

${ }^{5}$ Z. H. Jiang, Z. P. Yao, Y. P. Li, Y. D. Lv, and X. T. Sun, "Effect of Phosphate on Structure and Anticorrosive Properties of Ceramic Film Grown on Ti Alloy by Micro-Plasma Oxidation," Mater. Sci. Technol., 12, 75-9 (2004) (in Chinese).

${ }^{6}$ Z. H. Jiang, X. T. Sun, Y. P. Li, F. P. Wang, and Y. D. Lv, "Effect of the Oxidation Time on Properties of Ceramic Coatings Produced on Ti-6Al-4V by Micro-Arc Oxidation," Mater. Sci. Technol., 21, 281-4 (2005).

${ }^{7}$ A. L. Yerokhin, A. Leyland, and A. Matthews, "Kinetic Aspects of Aluminium Titanate Layer Formation on Titanium Alloys by Plasma Electrolytic Oxidation,' Appl. Surf. Sci., 200, 172-84 (2002).

${ }^{8}$ D. L. Boguta, V. S. Rudnev, and P. S. Gordienko, "Current Mode Effect on the Composition and Characteristics of Anodic-Spark Coatings," Prot. Met., $\mathbf{4 0}$ [3] 275-9 (2004).

${ }^{9}$ G. L. Yang, X. Y. Lv, Y. Z. Bai, H. F. Cui, and Z. S. Jin, "The Effects of Current Density on the Phase Composition and Microstructure Properties of Micro-Arc Oxidation Coating," J. Alloy. Compounds, 345, 196-200 (2002).

${ }^{10}$ Z. P. Yao, Z. H. Jiang, X. T. Sun, S. G. Xin, and Y. P. Li, "Influences of Current Density on Structure and Corrosion Resistance of Ceramic Coatings on Ti-6Al-4V Alloy by Micro-Plasma Oxidation," Thin Solid Film, 468, 120-4 (2004).

${ }^{11}$ Y. M. Wang, B. L. Jiang, T. Q. Lei, L. X. Guo, and Y. P. Cao, "Effects of Electrical Parameters on the Microstructure of Microarc Oxidation Ceramic Coatings on Ti6Al4V Alloy," J. Inorg. Mater., 18 [6] 1325-30 (2003) (in Chinese).

${ }^{12}$ Z. P. Yao, Z. H. Jiang, X. T. Sun, S. G. Xin, and Z. D. Wu, "Influence of the Frequency on the Structure and Corrosion Resistance of Ceramic Coatings on Ti-6Al-4V Alloy Produced by Micro-Plasma Oxidation," Mater. Chem. Phys., 92, 408-12 (2005).

${ }^{13}$ G. L. Schukin, A. L. Belanovich, V. P. Savenko, L. S. Ivashkevich, and V. V. Sviridov, "Micro-Plasma Anodic Oxidation of Aluminum and its Alloy Containing $\mathrm{Cu}$ in $\mathrm{K}_{2} \mathrm{ZrF}_{6}$ Solution," J. Appl. Chem, 69 [6] 939-41 (1996) (in Russian).

${ }^{14} \mathrm{X}$. W. Yu and C. N. Cao, "Study of Corrosion Resistance of Rare Earth Metal Conversion Coatings on A16061/SiC Petal Matrix Composites with Cyclic Anodic Polarization Curves," Chin. Rare Earths, 21 [3] 31-4 (2000) (in Chinese).

${ }^{15}$ D. Starosvetsky and I. Gotman, "TiN Coating Improves the Corrosion Behavior of Superelastic NiTi Surgical Alloy," Surf. Coat. Technol., 148, 268-76 (2001) 